\title{
ESTRUTURA E ORGANIZAÇÃO NA UNIVERSIDADE MULTICAMPI
}

\section{CELESTE MARIA PACHECO DE ANDRADE}

Universidade do Estado da Bahia (UNEB). Doutorado em História: História Social, Pontifícia Universidade Católica de São Paulo; Professora do Programa de Pós-Graduação Gestão e Tecnologias Aplicadas à Educação (GESTEC/UNEB) e do Programa de Pós-Graduação em História: História, Cultura e Práticas Sociais (PPGH/UNEB); Pesquisadora do Grupo de Pesquisa Educação, Universidade e Região - EduReg/UNEB; ORCID: 0000-0002-7308-8782.

E-mail: candrade@uneb.br

\section{LÍDIA BOAVENTURA PIMENTA}

Universidade do Estado da Bahia (UNEB). Doutorado em Educação, Universidade Federal da Bahia; Professora do Programa de Pós-Graduação Gestão e Tecnologias Aplicadas à Educação (GESTEC/UNEB); Coordenadora Adjunta da Unidade Acadêmica de Educação à Distância (UNEAD/UNEB); Pesquisadora do Grupo de Pesquisa Educação, Universidade e Região -

EduReg/UNEB; ORCID: 0000-0003-0936-9202. E-mail: lpimenta@uneb.br 


\section{ESTRUTURA E ORGANIZAÇÃO NA UNIVERSIDADE MULTICAMPI}

O estudo ocupa-se da estrutura organizacional da Universidade do Estado da Bahia, entre os anos de 2005 a 2015, indicando um quadro de mudanças e permanências que se associam às demandas internas e externas da instituição. Investiga as motivações e estratégias utilizadas nas alterações operadas na estrutura organizacional da instituição considerando o modelo multicampi. A partir de legislação específica e documentos da IES, adota-se uma natureza descritivo-qualitativa de pesquisa amparada numa perspectiva da gestão que considera a importância das alterações na estrutura organizacional na perspectiva de atender e acompanhar as características do modelo. O artigo faz uma exposição sobre o modelo multicampi, com ênfase na descentralização como forma de democratizar o acesso à educação superior e analisa a forma de organização da universidade com base no sistema de fluxo de organização e modelos de estrutura organizacional, que abrange a área acadêmica e administrativa. Conclui que a UNEB se estruturou para atender a exigências específicas da sua natureza multicampi no sentido de buscar a excelência que uma universidade pública e de qualidade almeja.

Palavras chave: Universidade. Organização Administrativa. Multicampi.

\section{ESTRUCTURA Y ORGANIZACIÓN EN LA UNIVERSIDAD MULTICAMPI}

El estudio aborda la estructura organizativa de la Universidad del Estado de Bahía, entre los años 2005 y 2015, indicando un marco de cambios y permanencias que se asocian con las demandas internas y externas de la institución. Investiga las motivaciones y estrategias utilizadas en los cambios realizados en la estructura organizativa de la institución considerando el modelo multicampi. Con base en la legislación específica y los documentos IES, se adopta una naturaleza descriptiva-cualitativa de la investigación basada en una perspectiva de gestión, que considera la importancia de los cambios en la estructura organizacional para cumplir y monitorear las características del modelo. El artículo hace una exposición sobre el modelo multicampi, con énfasis en la descentralización como una forma de democratizar el acceso a la educación superior y analiza la forma de organización de la universidad basada en el sistema de flujo organizacional y los modelos de estructura organizacional, que cubre el área académica. y administrativo. Concluye que la UNEB fue estructurado para cumplir con los requisitos específicos de su naturaleza multicampi para buscar la excelencia que busca una universidad pública y de calidad.

Palabras clave: Universidad. Organización Administrativa. Multicampi. 


\section{ORGANIZATIONAL STRUCTURES AT THE MULTICAMPI UNIVERSITY}

The study is about the organizational structure of the Universidade do Estado da Bahia, from 2005 to 2015, identifying the structural changes and stabilities,which are associated to internal and external institutional demand. The research is about motivations and strategies used on the organizational structure changes of the institution, considering the multi-campus model. Based on specific legislation and IES documents, it adopts a descriptive-qualitative research supported by a management perspective that considers the importance of the organizational structure changes, with perspective of meeting and monitoring the model's characteristics. The article presents the multi-campi model, with emphasis on decentralization as a way to democratize access to higher education and analyzes the way the university is organized based on the organizational flow system and organizational structure models, which covers the academic and administrative area. It concludes that UNEB has structured itself to meet the specific requirements of its multicampus nature in order to pursue the excellence that a public and quality university aspires to.

Keywords: University. Administrative Organization. Multicampi. 


\section{ESTRUTURA E ORGANIZAÇÃO NA UNIVERSIDADE MULTICAMPI}

\section{Introdução}

A instituição universidade, desde os seus primórdios tem preocupações específicas com a produção, divulgação e aplicação do conhecimento com vistas à melhoria das condições de vida da sociedade. Cumpre, portanto à instituição universitária impulsionar a pesquisa e o desenvolvimento científico, proporcionando a descoberta e a aplicação de novas tecnologias contribuindo desta maneira para o crescimento socioeconômico e cultural da comunidade, região e país onde está inserida. Além disse deve promover a extensão, aberta à participação da população visando a difusão das conquistas e benefícios resultantes do desempenho da instituição. Para além dessas funções baseadas em princípios administrativos e acadêmicos, a universidade tem responsabilidade também com a formação e titulação permanente de pessoal.

Essa diversidade de funções está associada a uma complexidade da estrutura universitária e, no caso da Universidade do Estado da Bahia, de natureza multicampi, motivou o seu redimensionamento exigindo no seu cotidiano um maior controle em busca de eficiência e eficácia institucional. De uma preocupação inicial com a pesquisa e o ensino, suas atividades foram se multiplicando, incorporando a necessidade de produção e disseminação do conhecimento, bem como a forma de controle e gestão da atividade acadêmica.

Além disso, o volume de ações concomitantes a serem realizadas resulta em uma interdependência das áreas finalística (acadêmica) e meio (manutenção), requerendo estrutura organizacional e processo decisório compatíveis com tais ações. Neste caso, devem-se enfatizar aspectos inerentes ao processo de gestão de unidade educacional, a saber: formação, conhecimento, tecnologia, qualidade, cultura, descentralização, priorização, comunidade, inclusão, eficiência, eficácia, efetividade, competividade, diversidade, inclusão, repetência, cidadania, questões acadêmicas e pedagógicas, evasão, equipe, em atenção às iniciativas da própria sociedade, que abrangem contexto de educação formal, socioambiental, econômico, político e cultural.

As mudanças nas sociedades colocaram em xeque o modelo de gestão das instituições de ensino superior, provocando uma grande discussão a partir da Declaração de Bolonha (1999) 
onde ficava patente que o modelo anterior deveria ser ultrapassado em busca de novas perspectivas da gestão universitária. O horizonte, por sua vez tem exigido das instituições universitárias o aprimoramento do processo de gestão e estrutura organizacional. Considerando o conceito de administração como o ato de planejar, organizar, dirigir e controlar as atividades de uma organização, diagnosticando deficiências e identificando aspectos positivos, estabelecendo metas, planos e programas para alcançar os objetivos estabelecidos, através de decisões e procedimentos (LACOMBE; HEILBORN, 2008), a gestão universitária orienta-se por objetivos institucionais e instrumentos básicos da gestão universitária, quais sejam: o Projeto Pedagógico Institucional (PPI), Plano de Desenvolvimento Institucional (PDI), Programa de Gestão, Planejamento de Execução Anual, Avaliação Institucional, Projetos Pedagógicos de Cursos. Acrescente-se a legislação baseada em princípios da administração pública: Plano Plurianual (PPA), Lei de Diretrizes Orçamentárias (LDO), Lei Orçamentária Anual (LOA) e a Programação Orçamentária e Financeira Anual, previstos no art. 165 a 169 da Constituição Federal de 1988, documentos que orientam as estratégias de ação de reitores, pró-reitores, diretores de unidade, coordenadores de colegiados de cursos de graduação e de pós-graduação.

Trata-se, portanto, de uma dinâmica, o fazer de uma instituição universitária, pois, a existência dos documentos institucionais perpassa ainda, um fazer educacional que não se desenvolve ajustado como um todo. Acrescido a isso deve-se levar em consideração que, a elaboração de cada documento institucional é produzida em conjunturas específicas e, com elas muito do que foi pensado para certo momento, perde o seu sentido por ocasião da organização das estratégias e metas de execução.

Quando a universidade possui estrutura multicampi e multirregional, ou seja, sua estrutura organizacional é composta por campi instalados em vários municípios ou vários departamentos em um município, a gestão deve ter como foco os objetivos estabelecidos para a instituição e não para um campus. Assim, o processo de tomada de decisão observa o todo e utiliza como subsídio os instrumentos aqui mencionados no sentido de melhor exercer ou dirigir as ações e estabelecer as prioridades. A questão nesse modelo de Universidade é que todos os campi representam um universo específico, onde as relações sociais estão envoltas em uma série de outras variáveis que terminam por representar desafios para o que se pretende como uma política universitária, capaz de dar sentido e homogeneizar as práticas universitárias por toda a instituição.

\section{plurais}


Desta maneira a estrutura dos órgãos que viabilizam a ação da universidade deve estar adequada e assegurar o fluxo das demandas acadêmicas e administrativas, de forma que encontre um caminho e consiga adequar suas propostas ao requisitado pelos seus diversos espaços comuns. Essa possível unidade dentro da diversidade talvez seja o maior exercício de gestão na Instituição, diante de um modelo multifacetado como é o multicampi.

O tema despertou interesse e motivou as autoras por criar-lhe oportunidades para realizar estudos em duas áreas sempre presentes no seu dia a dia: a instituição de educação superior cuja intenção respalda-se no desenvolvimento de suas atividades profissionais área de concentração de pesquisa, a outra gestão em instituição universitária. Trata-se, portanto, de uma reflexão implicada, isso porque a vida no seu cotidiano é vivenciada de forma a necessitar de um olhar que leve em consideração as exigências da pesquisa sobre as questões específicas motivadoras desse estudo e, mais o fato de vivenciar tais questões fazem das autoras testemunhas privilegiadas de uma problemática em si.

O estudo nasce do seguinte questionamento: considerando o modelo multicampi, quais as estratégias adotadas pela Universidade do Estado da Bahia (UNEB) para alterar a sua estrutura organizacional? Esse olhar, faz com que se tenha uma perspectiva da gestão, de conhecer as alterações na estrutura e ao mesmo tempo, conjecturar sobre a perspectiva de atender e acompanhar as características do modelo.

Registre-se que a UNEB possui modelo multicampi e multirregional, com sede em 24 municípios baianos e, integra a administração pública estadual, sendo mantida pela autarquia Universidade do Estado da Bahia, vinculada à Secretaria de Educação do Estado e, como tal, deve seguir as orientações definidas na legislação, não podendo dela se afastar sob pena de responder aos ditames da lei.

Entre os anos de 2005 e 2015 ocorreram diversas alterações na estrutura organizacional da UNEB. Foram dez anos de modificações em termos de criação de novos órgãos ou alteração de competências e contribuíram para implementar modificações significativas nas formas de estruturação das rotinas administrativas entre docentes, servidores técnicos administrativos e discentes. 
Para o desenvolvimento da pesquisa e a discussão dos seus resultados é importante destacar que esta é uma pesquisa de natureza descritiva, por limitar-se à análise das características das modificações na estrutura organizacional da instituição universitária, sem propósito de explicar o fenômeno abordado. Esse modelo de pesquisa qualitativa é reconhecido como adequado para o estudo de uma unidade de estudo delimitada. Neste contexto, Roesch (2005) acrescenta a importância da pesquisa, quando realizada em estudo de organizações e suas estruturas de funcionamento.

O artigo desdobra-se em três pontos. Inicia com uma exposição sobre o modelo multicampi, enfatizando a descentralização como forma de democratizar o acesso à educação superior, segue com uma análise sobre a forma de organização da universidade a partir da estrutura acadêmica e administrativa e, finaliza com a reflexão sobre estrutura organizacional no modelo multicampi: da Universidade do Estado da Bahia.

\section{MODELO MULTICAMPI: descentralização para democratizar o acesso}

O subtítulo remete a uma questão muito presente nos anos oitenta do século XX, quando a preocupação dos pensadores da educação era a forma como ampliar o acesso ao ensino superior. E, de fato houve uma expansão de vagas mas, em instituições privadas. Numa sociedade desigual, principalmente em termos de recursos financeiros e de oportunidades de ascensão, grande parte da população não teve acesso às instituições de ensino superior da iniciativa privada. Essa realidade exigia a ampliação do número de vagas entre as instituições estaduais de ensino.

As universidades estaduais paulistas tomaram a dianteira na expansão de suas vagas e na criação de faculdades isoladas, que, mais tarde se tornaram universidades estaduais. A esse respeito Edivaldo Machado Boaventura (2009, p. 8) faz a seguinte reflexão:

Era importante conhecer de perto a experiência da UNESP. Experiência de uma universidade multicampi, brasileira e paulista, interna e estadual. Trouxe a Salvador o professor Armando Otávio Ramos, à época, reitor da UNESP, um dos seus fundadores, ex-vice-reitor, que se entusiasmou pela ideia e mostrou seus êxitos e vicissitudes. $\mathrm{O}$ reitor paulista forneceu amplo material sobre a universidade que dirigia, desde a lei de criação até normas e pareceres internos, colocando-se inteiramente às ordens para ajudar.

\section{plurais}


O termo multi vem do latim multus, a um, que significa muito, "copioso, frequente, numeroso", conforme José Cretella Júnior e Geraldo e Ulhoa Cintra, Dicionário Latino-Português (1953, p. 760). Antônio Houaiss (2000, p. 1976) traduz o termo como "abundante, em grande quantidade". O vocábulo multicampi surge da junção das partículas multi, multus, com, campus, campi, em Vergilius "o lugar em que se faz algum exercício". (CRETELLA JÚNIOR, ULHOA CINTRA, 1953, p. 169).

O que há em comum nessa busca pela dicionarização do vocábulo é que, elas exprimem a ideia geral que se pretende ao pensar uma instituição que está presente em vários locais e que exprimem a capacidade de cada grupo em apresentar as suas especificidades e fortalecer a cidade/ região onde estão implantadas. No caso específico da UNEB, há que acrescentar que a instituição está presente em dezenove dos vinte e sete Territórios de Identidade, nos quais o estado da Bahia está dividido para efeito de planejamento e ação da Administração Pública Estadual.

A universidade multicampi é composta por mais de um campus, propiciando a descentralização administrativa e dispersão físico-geográfica, com reflexo nas dimensões acadêmicas, organizacionais e espaciais (FIALHO, 2005). A autora enfatiza que o campus universitário "é um espaço contínuo, delimitado e exclusivo, onde se reúnem os edifícios de uma universidade, podendo estar situado dentro da cidade, na sua periferia ou fora dela. A idéia-limite do campus consiste no território que reúne todas as instalações de uma universidade. (CUNHA, L. A., 1998, p. 74 apud FIALHO, 2005, p. 53)".

A referida dispersão dentre outros aspectos, diz respeito às relações entre regiões geográficas e centros urbanos, aos diversos cenários históricos, culturais, educacionais, sociais, econômicos, demográficos, em decorrência das diferentes regiões onde os campi estão instalados, exigindo da instituição uma articulação entre os fatores externos e o que é abordado e discutido no seu ambiente interno e, em seguida difundido na sociedade.

Entretanto chama a atenção a necessidade de uma discussão sobre a questão territorial. $\mathrm{O}$ Brasil é um país onde suas dimensões territoriais comportam modelos diferentes e diferenciados de instituições educacionais em seus sistemas de educação. Desta forma, entende-se que o modelo multicampi de universidade não está alheio às condições materiais brasileiras e suas demandas por educação superior pública. É nesse quadro que se efetiva o propósito de universidade que, ao se 
encarregar de formar o profissional e cidadão, de prover e socializar a pesquisa, expressa, também, a estrutura e o funcionamento da sociedade na qual está inserida.

Acrescenta Chauí (2005), que na instituição universitária existe cotidianamente a convivência de diversidade de opiniões, atitudes e projetos que ressaltam as divisões e contradições da sociedade. A universidade multicampi e multirregional atua de modo mais próximo às comunidades nas quais seus campi estão situados e, portanto, traz na sua ação as demandas, valores e costumes destas. $\mathrm{O}$ raciocínio é pertinente nos aspectos subjetivos, considerando que na própria estruturação de um campus, a escolha dos cursos a serem ofertados tem relação com as características das localidades onde estão instalados. Essa especificidade vez por outra interfere nos embates que devem ser registrados diante de uma política de reestruturação da Universidade, ponto destacado neste estudo.

O modelo de estrutura multicampi da universidade abrange dimensões territoriais, em relação às regiões geográficas e centros urbanos; espaço-temporais e funcionais que dizem respeito aos cenários históricos, culturais, interagindo com os valores locais e regionais; bem como, ações funcionais e áreas de conhecimento, as quais têm efeitos diretos no desenvolvimento das atividades e projetos, agregando cursos, docentes e discentes.

O modelo multicampi é favorável a proporcionar o acesso à educação superior mais próximo do local de residência e vivência das pessoas. Assim, com o objetivo de proporcionar a formação de professores para o próprio sistema de ensino, o Governo do Estado da Bahia, a partir da década de sessenta decidiu pela expansão do ensino superior no interior do Estado. Faz parte da política pública resultante da expansão, a criação de Faculdades de Formação de Professores, de maneira a permitir a permanência dos candidatos à formação profissional em suas regiões. Dessa forma, o pessoal qualificado permaneceria no município de origem contribuindo para o desenvolvimento de sua região.

A estratégia adotada pelo Governo consistiu em implantar nos "municípios capitais regionais entidades deste nível de ensino para atender, primeiramente, à demanda educacional e, em segundo lugar, responder às necessidades sociais e econômicas pela formação de quadros profissionais." (BOAVENTURA, 2005, p. 03). Segundo o autor:

\author{
plurais


Em 1983, a administração contava com a Universidade Estadual de Feira de Santana, já autorizada, com a Universidade do Sudoeste e a Superintendência de Ensino Superior do Estado da Bahia (SESEB), composta pelo Centro de Educação Técnica da Bahia (CETEBA), e pelas Faculdades de Agronomia do Médio São Francisco, de Formação de Professores de Alagoinhas, Jacobina e Santo Antônio de Jesus, e Filosofia, Ciências e Letras, de Caetité. Essa situação resultou da Lei Delegada Estadual número 12, de 30 de dezembro de 1980, conforme decisão do governador Antônio Carlos Magalhães e do seu secretário Eraldo Tinôco. (BOAVENTURA, 2009, p. 05)

No conjunto das discussões sobre a interiorização do ensino superior na Bahia, surgiu, então, o embrião da Universidade do Estado da Bahia (UNEB), criada no início da década de oitenta sob o modelo multicampi, estruturada a partir da reunião das citadas Faculdades.

A UNEB tem por objetivo promover a formação integral do cidadão e o desenvolvimento das potencialidades econômicas, tecnológicas, sociais, culturais, artísticas e literárias da comunidade baiana, sob a égide dos princípios da ética, da democracia, das ações afirmativas, da justiça social, pluralidade étnico-cultural e demais princípios do Direito Público, conforme dispõe o $\S 2^{\circ}$ do art. $1^{\circ}$ do seu Regimento Geral.

O citado Regimento Geral, no intuito de valorizar o modelo multicampi e multirregional da UNEB, considerando as unidades acadêmicas instaladas com sede em 24 cidades do estado da Bahia, faculta à Universidade a adoção de administração compatível com a necessidade do funcionamento de sua estrutura organizacional, incorporando princípios de descentralização, de economicidade e de cooperação recíproca. (Art. $6^{\circ}$ do Regimento Geral, 2011).

Ressalte-se que a gestão da universidade mulicampi implica em entender a oferta da educação superior de forma única e orgânica em todos os campi, implementando o planejamento acadêmico e financeiro de forma orgânica e institucional. Assim favorece o controle da qualidade das ações e a otimização na aplicação dos recursos, além de proporcionar maior integração com a comunidade (número maior de pessoas), considerando as peculiaridades regionais e as novas demandas em decorrência das mudanças da sociedade, conforme mencionado anteriormente.

Antes da reforma que reestruturou as Universidades Estaduais baianas, em 1997, a UNEB tinha sua estrutura acadêmica composta por faculdades, de forma que havia diferenciação na gratifi- 
cação da remuneração pelos cargos de diretores de Faculdade. Após a citada reforma as faculdades passaram a se constituir em Departamentos, unidades universitárias responsáveis diretamente pela oferta de cursos, fomento da pesquisa e extensão. Na atualidade os trinta departamentos compõem a administração setorial da Instituição, os quais se constituem em unidades acadêmicas e gozam de autonomia nos limites de sua competência, são responsáveis pelo planejamento, execução, avaliação das atividades didático-científicas e administrativas e, ainda, pela gestão administrativa, patrimonial, orçamentária, financeira e política.

\section{ESTRUTURA ACADÊMICA E ADMINISTRATIVA: organizando a ação da Universidade}

Para a compreensão de como as instituições universitárias funcionam e cumprem o seu papel na sociedade, há que se conhecer como se caracteriza a estrutura organizacional da instituição, ou seja, o modelo de gestão adotado. Tais itens retratam a instituição em relação à organização, funcionamento e dinâmica do processo decisório.

Por estrutura organizacional entende-se como o "conjunto de elementos articulados entre si de forma que cada elemento é interdependente" (APPOLINÁRIO, 2004). Considere-se que a estrutura é tida como o que há de mais permanente em uma organização, em contraste com sistema, que é, por definição, dinâmico. Ainda pode-se considerar, teoricamente, a oposição entre estrutura e conjuntura, isto é, o que permanece e o que muda por contingência do ambiente em dado momento, o que se aplica também à instituição universitária.

A estrutura de uma organização também é entendida como a soma das maneiras pelas quais o trabalho é dividido em tarefas distintas e, em seguida, como a coordenação é realizada entre essas tarefas. Os elementos da estrutura devem ser escolhidos, visando a obtenção de uma consistência ou harmonia interna e, ainda, as características da organização, ou seja, entre outras, seu tamanho, idade, tipo de ambiente em que atua, sistema técnico que utiliza (MINTZBERG, 2003).

Em especial, as universidades brasileiras, após a Reforma Universitária de 1968, conforme previsto na legislação, a estrutura organizacional é composta pela coordenação sistêmica entre departamentos e colegiados. Assim, foram instituídos os departamentos, caracterizando-se como

\section{plurais}


a célula básica da universidade, cuja subdivisão não é possível, com a finalidade de servir a toda a universidade (HARY E FACHIN, 2000, p. 15).

Observando-se os atos constitutivos da universidade em estudo, seu estatuto e seu regimento geral, aprovados pelos órgãos competentes, verifica-se a existência de duas situações em sua estrutura. Em uma estão os cursos e programas inerentes às áreas de ensino, pesquisa, extensão, cuja responsabilidade pela criação, execução, acompanhamento e avaliação está a cargo dos colegiados de curso, departamentos e o Conselho de Ensino, Pesquisa e Extensão (CONSEPE), entendidos como componentes da estrutura denominada acadêmica. Na outra, a Reitoria, composta pelas Pró-Reitorias, Conselho Universitário (CONSU), suplementares de Natureza Interdisciplinar e Órgãos de Apoio Acadêmico-Administrativo, integram a estrutura executiva, de natureza administrativa e, a partir dos objetivos ou atribuições de cada um desses órgãos, foram inseridas as suas respectivas estruturas.

Acrescente-se que, com a finalidade de assegurar e dirigir os sistemas de fluxos que viabilizam o funcionamento da instituição e definir os inter-relacionamentos das suas diferentes partes, em termos gerais, uma organização, segundo Mintzberg (2003) está estruturada em cinco níveis:

a) núcleo operacional, que envolve os membros da instituição que executam as atividades diretamente relacionadas com a finalidade da organização;

b) cúpula estratégica, cuja responsabilidade consiste em assegurar que a organização cumpra a sua missão, apresentando resultados eficazes, bem como que atenda aos anseios dos que a controlam ou que detêm poder sobre ela, a exemplo de órgãos governamentais ou proprietários e acionistas;

c) linha intermediária que consiste no elo entre o núcleo operacional e a cúpula estratégica, representada pela cadeia de gerentes com autoridade formal, proporcional ao seu porte e à confiança na supervisão direta para coordenação;

d) tecnoestrutura, composta por analistas que desenvolvem formas de padronização, com o objetivo de tornar mais eficaz o trabalho das pessoas que atuam na instituição, em atenção às contingências impostas pelo ambiente externo; $\mathrm{e}$,

e) assessoria de apoio, composta por unidades especializadas, criadas para apoiar a organização fora de seu fluxo de trabalho operacional. 
De acordo com o autor, a constituição da estrutura de uma instituição é essencial para que se proceda à seleção de elementos ou parâmetros delineadores de influência direta na divisão do trabalho e nos mecanismos de coordenação.

Assim, a divisão do trabalho é responsável pelo agrupamento e pela dimensão das unidades como parâmetros delineadores da estrutura ou da hierarquia da instituição. Por outro lado, diz respeito, também, à especialização das tarefas, à formalização do comportamento, ao treinamento e à doutrinação, como referências individuais da comunidade acadêmica da instituição.

Em relação a esses parâmetros que influenciam na coordenação do trabalho, Mintzberg (2003) destaca os sistemas de planejamento e controle, os instrumentos de interligação ou coordenação e, ainda, a descentralização que tem relação com o processo de tomada de decisão.

Além da divisão do trabalho e dos mecanismos de coordenação, a estrutura da instituição universitária sofre a influência da especialização. Esta, em uma dimensão horizontal, corresponde à subdivisão das tarefas desenvolvidas pelas pessoas e é resultado da repetição de atividades e procedimentos padronizados. Nesse vetor não se destacam muitas diferenciações nas ações executadas, pois de menor complexidade e de responsabilidade limitada, não exigiria de seus executores ações que fugissem ao determinado pela norma. Contudo na universidade a especialização faz a diferença, posto que seus docentes atuam com as especificidades inerentes às áreas de conhecimento e, portanto, são especialistas.

Já a dimensão vertical caracteriza-se pela supervisão e controle do trabalho pelas autoridades hierarquicamente competentes, o que exige uma maior responsabilidade pelos desdobramentos dos atos administrativos, o controle daqueles atos executados por terceiros e as consequências das decisões tomadas e registradas dos documentos internos físicos ou via sistemas informatizados institucionais.

No âmbito da universidade multicampi, objeto de estudo desta pesquisa, as unidades acadêmicas constituem o referência principal de especialização horizontal; a estrutura vertical é composta pelos níveis hierárquicos existentes compostos por docentes e técnicos administrativos que, por analogia, representam o núcleo operacional e a Reitoria, esta correspondendo à cúpula estratégica.

\section{plurais}


Mintzberg (2003) complementa que os padrões para estabelecer o "design estrutural" da instituição devem ser influenciados pela sua idade e tamanho, como mencionado e pelo sistema técnico que adota, pelo ambiente em que opera, bem como pelos relacionamentos de poder que a circundam e a inspiram. Esses dois elementos são muito interessantes por duas características iniciais: a primeira diz respeito ao fato de que em uma instituição consolidada, mais antiga, seus procedimentos já estão cristalizados e as mudanças encontram maiores dificuldades para mudanças ou mesmo atualização de procedimentos. Exemplo disso é o uso das tecnologias da informação, onde os processos administrativos começaram a ser virtuais e há resistências ao uso; a segunda diz respeito à dimensão da instituição. A centralização institucional contribui para um maior controle e padronização dos procedimentos e numa instituição de pequeno porte esses controles são mais próximos e, portanto, passíveis de uma maior fiscalização.

Desta forma, ainda segundo Mintzberg (2003), os modelos da composição de estrutura e os fatores situacionais devem ser agrupados de maneira a estabelecer o que ele denomina de configurações básicas de uma organização, ora apresentadas:

a) estrutura simples, a qual caracteriza uma organização com pequena estrutura, poucos assessores de apoio, divisão de trabalho sem rigor. A cúpula estratégica tem o poder sobre as decisões, identificando-se uma pequena hierarquia gerencial baseada na supervisão direta. Há pouca formalização e uso mínimo do planejamento e treinamento;

b) burocracia mecanizada, baseada na padronização dos processos de trabalho, com tarefas operacionais rotineiras a altamente especializadas. É o modelo de estrutura mais próximo ao que Max Weber criou, caracterizado por ter responsabilidades, qualificações, canais de comunicação e normas de trabalho padronizadas, além de possuir hierarquia de autoridade claramente definida. O núcleo operacional possui procedimentos formalizados por normas e regulamentos, bem como o sistema de comunicação preciso em toda a organização;

c) burocracia profissional, caracterizada pela coordenação da padronização das habilidades, na qual o núcleo operacional é composto por profissionais especializados contratados e detentores de "considerável controle sobre seu próprio trabalho". Assim, agem de maneira independente, institucionalizando a autoridade de natureza profissional. Contudo, a estrutura é burocrática e a coordenação é exercida com a adoção dos padrões estabelecidos previamente e observados pelo núcleo operacional especializado. Há uma forte descentralização e a formulação de estratégias é efetivada por meio das iniciativas de seus membros, prevalecendo aquelas que forem melhor defendidas. Este modelo evidencia 
duas situações para a gestão, a saber: a autonomia outorgada aos profissionais quanto à escolha de como e quando desempenhem suas atividades, podendo dificultar a prestação do serviço, bem como a possibilidade de ignorar as necessidades da organização;

d) forma divisionalizada, na qual a estrutura é dividida de acordo com a demanda a atender, o que implica em cada divisão ter uma estrutura própria de ação. A descentralização é relativa, posto que seja restrita à coordenação das divisões. A cúpula estratégica delega ampla autonomia para que as divisões tomem as decisões, acompanhando e monitorando os resultados a partir dos padrões estabelecidos. Porém, como somente a cúpula possui o conhecimento detalhado sobre a organização, esta pode incentivar e influenciar nas decisões de duas ou mais divisões, combinadas, o que resultará no comprometimento da autonomia de cada divisão;

e) adhocracia, consistindo na configuração mais nova e mais complexa entre as cinco apresentadas pelo autor, demonstrando menor reverência aos princípios clássicos da administração. O processo de informação e de decisão fluem de maneira flexível e informal, facultando a implementação de inovações onde quer que se façam necessárias, muitas vezes sem obedecer à cadeia de autoridade. Baseia-se na contratação de especialistas, os quais devem unir esforços em equipes multidisciplinares responsáveis por um projeto específico. A estes são concedidos poderes necessários à execução das ações previstas. O processo de tomada de decisão acontece no âmbito de gerentes e não gerentes em todos os níveis hierárquicos, a depender da natureza da decisão a ser tomada.

O sistema de fluxo e tipos de estrutura existentes em qualquer organização, apresentados por Mintzberg, possibilita a análise da estrutura de uma organização, no caso a universidade. No sentido de contextualizar quanto a estrutura na administração do ensino superior, Hardy e Fachin (2000), discorrem:

\footnotetext{
a) burocracia, com ajustes ao conceito tradicional de Weber, com a finalidade de combinar características burocráticas e profissionais, tendo em vista a necessidade de adotar estruturas administrativas que promovam a coordenação e direção exigidas em razão do aumento do tamanho e complexidade das instituições universitárias ocorrido no mundo;

b) colegialidade, "comunidade de letrados" ou "scholars" (HARDY e FACHIN, 2000, p. 23), entendida como a descentralização dentro dos órgãos, resultado da "ocorrência de um alto grau de influência dos membros do corpo docente no processo decisório" (HARDY e FACHIN, 2000, p. 23);
}

\section{plurais}


c) modelo político, desenvolvido por Baldrige (1971 apud HARDY e FACHIN 2000), que utilizou teorias do conflito, do poder em comunidades e de grupos de interesse, além de sua pesquisa sobre a tomada de decisão por consenso, com o intuito de elaborar o quadro para a análise política desse modelo, identificando uma visão "intensamente política da vida universitária" (HARDY e FACHIN, 2000, p. 25).

Assim registra o mencionado autor:

\begin{abstract}
Nós não vemos nem os rígidos aspectos formais da burocracia nem os elementos de um "colégio" acadêmico, repletos de tranqüilidade e de busca do consenso. Pelo contrário, se rebeliões estudantis incapacitam o campus, se professores formam sindicatos e fazem greve, se administradores defendem suas posições tradicionais, e se grupos de interesse externos e governantes irados invadem os saguões acadêmicos, todos esses atos devem ser visualizados como políticos. (BALDRIDGE, 1971 apud HARDY e FACHIN, 2000, p. 25).

d) anarquia organizada ou garbage can, quando as "decisões não são tomadas intencionalmente, sendo determinadas por ausência de ação ou por acidente" (HARDY e FACHIN, 2000, p. 27), tendo como premissa que o comportamento administrativo decorre de ambiguidades nas preferências, na tecnologia e na participação. Os autores ressaltam que os responsáveis pela concepção deste modelo estabelecem limites para a sua utilização, sendo mais propícia se existir um líder que adote o papel de agregar ou quando houver folga de recursos.
\end{abstract}

Mintzberg (2003) abordou os modelos de estrutura forma geral, Hardy e Fachin (2000) enfatizam os modelos no ambiente universitário. A discussão sobre estrutura organizacional na instituição universitária neste estudo apresenta características que a aproximam do modelo burocrático, em cujo modelo as organizações são redes de grupos sociais, dedicadas a determinados fins e organizadas para uma eficiência máxima. (BALDRIDGE apud FINGER, 1988), bem como da burocracia profissional, coma atuação dos professores em áreas específicas de conhecimento, combinada ainda com a colegialidade, com decisões a partir do grupo.

\title{
UNIVERSIDADE DO ESTADO DA BAHIA: estrutura organizacional no modelo multicampi
}

Conforme mencionado anteriormente a UNEB está estruturada sob a forma do sistema multicampi de educação superior, com sede e foro na Cidade do Salvador e jurisdição em todo o 
território baiano, de acordo com o disciplinado na Lei Delegada n. ${ }^{\circ} 66$, de $1^{\circ}$ de junho de 1983. À época de sua criação, oferecia basicamente: a) cursos de formação de professores nos seus nove campi, respectivamente nos municípios de Salvador, Alagoinhas, Jacobina, Santo Antonio de Jesus, Caetité, Senhor do Bonfim, Paulo Afonso e Barreiras; b) curso de engenharia agronômica na cidade de Juazeiro; e, c) curso de Graduação de Professores da Parte de Formação Especial do Currículo de Ensino de $2^{\circ} \mathrm{Grau}$, com habilitação em administração, construção civil, eletricidade, nutrição e dietética e química aplicada, no Centro de Ensino Técnico da Bahia (CETEBA), em Salvador.

A partir de 1986, a universidade começa oferecer cursos em outras áreas de conhecimento a exemplo de Desenho Industrial, Ciências Contábeis e Comunicação Social. Atualmente a UNEB tem responsabilidade com o desencadeamento de ações nas tradicionais áreas do conhecimento: Ciências Exatas e da Terra, Ciências Biológicas, Engenharias, Ciências da Saúde, Ciências Agrárias, Ciências Sociais Aplicadas, Ciências Humanas, Linguística, Letras e Artes, com o objetivo de promover a formação integral do cidadão e o desenvolvimento das potencialidades econômicas, tecnológicas, sociais, culturais, artísticas e literárias da comunidade baiana, sob a égide dos princípios da ética, da democracia, das ações afirmativas, da justiça social - dos direitos humanos -, pluralidade étnico-cultural e demais princípios do Direito Público, conforme dispõe o Art. $1^{\circ}$ do Estatuto (BAHIA, 2012), nos seus 29 Departamentos, situados no campus capital e em 23 municípios baianos.

Salienta-se que a UNEB foi reestruturada pela Lei Estadual $n^{\circ} 7176 / 1997$, quando a base de sua estrutura acadêmica passa a ser de Departamentos, em substituição às unidades universitárias, antes denominadas faculdades ou centros. Desta forma, ficou instituído o sistema binário na estrutura da universidade, cuja cadeia de instâncias de decisão constituiu-se em Reitoria, Departamento e Colegiado de Curso, em substituição ao sistema ternário, que envolvia a Reitoria, as Faculdades ou Centros, os Departamentos e Colegiados. Há que se registrar que a mencionada Lei Estadual $\mathrm{n}^{\circ} 7176 / 1997$ foi revogada pela Lei Estadual $\mathrm{N}^{\circ}$ 13.466, de 22 de dezembro de 2015, contudo a estrutura organizacional da UNEB ainda permanece com base nos departamentos, conforme previa a lei anterior.

Nesta época foram incorporados os Órgãos Suplementares de Natureza Interdisciplinar, vinculados à Reitoria ou aos Departamentos com a atribuição de desenvolver atividades finalísticas e

\author{
plurais


meio, em contribuição ao alcance pleno da missão, diretrizes e objetivos da Universidade, de acordo com o expresso no Art. 31 do Estatuto (BAHIA, 2012). Na ocasião, são denominados, também, Órgãos de Apoio Acadêmico-Administrativo (Art. 32), vinculados à administração superior, aos quais competem apoiar o funcionamento da instituição universitária através de ações de natureza finalística ou administrativa, conforme exemplos a seguir, em atenção ao disposto no Anexo III do Estatuto da UNEB: Secretaria Geral de Cursos (SGC), Secretaria Especial de Registro de Diplomas e Certificados (SERDIC), Comitê de Ética na Pesquisa (CEP), Teatro UNEB, Memorial Antônio Conselheiro, Parque Estadual de Canudos, Centro de Processos Seletivos (CPS) (BAHIA, 2012).

Assim, observa-se que a estrutura organizacional da UNEB tem por suporte inicial a Administração Superior, composta pelos Conselhos Superiores e Reitoria formada pelas Pró-Reitorias, Secretarias, Órgãos Suplementares de Natureza Interdisciplinar e os Órgãos de Apoio Acadêmico-Administrativo. Em seguida, está a Administração Setorial, constituída pelos departamentos e seus órgãos, a fim de suprir a área acadêmica e administrativa, conforme dispõem o art. $7^{\circ} \mathrm{e}$ o art. 16 do Regimento Geral da Instituição, a saber: a) Órgãos Deliberativos da Administração Superior - Conselho Universitário (CONSU), Conselho Superior de Ensino, Pesquisa e Extensão (CONSEPE), Conselho de Administração (CONSAD); b) Órgãos Executivos da Administração Superior que compõem a Reitoria-Gabinete do Reitor, Vice-Reitoria, Assessoria Especial (ASSESP), Procuradoria Jurídica (PROJUR), Pró-Reitoria de Graduação (PROGRAD), Pró-Reitoria de Pesquisa e Ensino de Pós-Graduação (PPG), Pró-Reitoria de Extensão (PROEX), Pró-Reitoria de Assistência Estudantil (PRAES), Pró-Reitoria de Planejamento (PROPLAN), Pró-Reitoria de Administração (PROAD), Pró-Reitoria de Gestão e Desenvolvimento de Pessoas (PGDP), PróReitoria de Infraestrutura (PROINFRA), Unidade de Desenvolvimento Organizacional (UDO), Ouvidoria, Órgãos Suplementares de Natureza Interdisciplinar, Órgãos de Apoio Acadêmico-Administrativo; c) Órgãos de Administração Setorial - Conselhos de Departamento, Departamentos, Colegiados de Curso, Núcleos de Pesquisa e Extensão (BAHIA, 2012).

Com o propósito de subsidiar a análise concernente à discussão motivadora deste estudo - as alterações na estrutura organizacional na Universidade do Estado da Bahia - o Quadro 1 apresenta um comparativo entre a estrutura em 2005 e a estrutura atual, posterior às alterações ocorridas até a 2015. 
Registre-se que este estudo busca entender as alterações implementadas na estrutura organizacional da UNEB, e, desta forma, não abrange a discussão concernente à Administração Setorial, Órgãos Suplementares de Natureza Interdisciplinar e Órgãos de Apoio Acadêmico-Administrativo, os quais são objeto de pesquisa complementar.

Na coluna denominada "Atribuições" correspondem àquelas previstas no Regimento Geral atual (BAHIA, 2012). Na coluna "Competência na Estrutura Organizacional 2005" constam as indicações dos órgãos competentes em relação às atribuições dispostas no Regimento Geral à época, conforme Resolução CONSU n ${ }^{\circ}$ 324/2005. Utilizando das disposições da pesquisa documental, o estudo comparativo é possível a partir das informações constantes na coluna "Competência na Estrutura Organizacional em 2006 a 2015”, em atenção ao descrito no Regimento Geral da UNEB, aprovado pela Resolução CONSU nº 864/2011.

Quadro 1 Comparativo das Atribuições dos Órgãos da Administração Superior da Estrutura Organizacional da UNEB no período 2006 a 2015

\begin{tabular}{|l|l|l|}
\hline \multicolumn{1}{|c|}{ Atribuição } & $\begin{array}{c}\text { Competência na Estru- } \\
\text { tura Organizacional } \\
\text { em 2005 }\end{array}$ & $\begin{array}{c}\text { Competência na Es- } \\
\text { Con } \\
\text { trutura Organizacio- } \\
\text { nal em 2006 a 2015 }\end{array}$ \\
\hline $\begin{array}{l}\text { Deliberativa, responsável pela formulação da Polí- } \\
\text { tica Universitária, definição das práticas gerais das } \\
\text { áreas acadêmica e administrativa e funciona como } \\
\text { instância revisora, em grau de recurso, das deli- } \\
\text { berações relativas ao âmbito de sua competência } \\
\text { (BAHIA, 2012). }\end{array}$ & CONSU & CONSU \\
\hline $\begin{array}{l}\text { Consultiva e deliberativa, responsável pela de- } \\
\text { finição da organização e funcionamento da área } \\
\text { acadêmica nos aspectos técnicos, didáticos e cien- } \\
\text { tíficos (BAHIA, 2012). }\end{array}$ & CONSEPE & CONSEPE \\
\hline $\begin{array}{l}\text { Administração e fiscalização econômico-financeira } \\
\text { da Universidade, incumbido de assegurar o regular } \\
\text { funcionamento da entidade (BAHIA, 2012). }\end{array}$ & CONSAD & CONSU \\
\hline
\end{tabular}

\section{plurais}




\begin{tabular}{|c|c|c|}
\hline $\begin{array}{l}\text { Representação social da Universidade, atuando } \\
\text { como facilitador das articulações da organização } \\
\text { universitária com a comunidade externa - baia- } \\
\text { na, brasileira e internacional, composto também } \\
\text { pela Vice-Reitora e Chefia de Gabinete (BAHIA, } \\
\text { 2012). }\end{array}$ & Gabinete do Reitor & Gabinete do Reitor \\
\hline $\begin{array}{l}\text { Execução, coordenação e acompanhamento das } \\
\text { atividades relacionadas com o ensino de graduação } \\
\text { (BAHIA, 2012). }\end{array}$ & $\begin{array}{l}\text { Pró-Reitoria de Ensino } \\
\text { de Graduação (PRO- } \\
\text { GRAD) }\end{array}$ & $\begin{array}{l}\text { Pró-Reitoria de Ensino } \\
\text { de Graduação (PRO- } \\
\text { GRAD) }\end{array}$ \\
\hline $\begin{array}{l}\text { Execução, coordenação e acompanhamento das } \\
\text { atividades de ensino de pós-graduação e dos cur- } \\
\text { sos de aperfeiçoamento, bem como pelo desenvol- } \\
\text { vimento de estudos e elaboração de programas de } \\
\text { pesquisa (BAHIA, 2012). }\end{array}$ & $\begin{array}{l}\text { Pró-Reitoria de Pesquisa } \\
\text { e Ensino de pós-gradua- } \\
\text { ção (PPG) }\end{array}$ & $\begin{array}{l}\text { Pró-Reitoria de Pesqui- } \\
\text { sa e Ensino de pós-gra- } \\
\text { duação (PPG) }\end{array}$ \\
\hline $\begin{array}{l}\text { Assessoramento, acompanhamento, supervisão e } \\
\text { coordenação das atividades relativas à extensão, à } \\
\text { cultura e à arte, bem como ao esporte e recreação } \\
\text { (BAHIA, 2012). }\end{array}$ & $\begin{array}{l}\text { Pró-Reitoria de Extensão } \\
\text { (PROEX) }\end{array}$ & $\begin{array}{l}\text { Pró-Reitoria de Exten- } \\
\text { são (PROEX) }\end{array}$ \\
\hline $\begin{array}{l}\text { Assessoramento técnico-administrativo, planeja- } \\
\text { mento, gerenciamento, execução, acompanhamen- } \\
\text { to, controle e avaliação das atividades de adminis- } \\
\text { tração geral e patrimonial. }\end{array}$ & $\begin{array}{l}\text { Pró-Reitoria de Admi- } \\
\text { nistração (PROAD) }\end{array}$ & $\begin{array}{l}\text { Pró-Reitoria de Admi- } \\
\text { nistração (PROAD) }\end{array}$ \\
\hline $\begin{array}{l}\text { Órgão técnico de assessoramento, responsável } \\
\text { pelo planejamento, programação, orçamento, } \\
\text { acompanhamento dos planos - global e setoriais. }\end{array}$ & $\begin{array}{l}\text { Pró-Reitoria de Planeja- } \\
\text { mento (PROPLAN) }\end{array}$ & $\begin{array}{l}\text { Pró-Reitoria de Plane- } \\
\text { jamento (PROPLAN) }\end{array}$ \\
\hline $\begin{array}{l}\text { Assessoramento jurídico, responsável pela repre- } \\
\text { sentação judicial e extrajudicial. }\end{array}$ & \begin{tabular}{|l|}
$\begin{array}{l}\text { Procuradoria Jurídica } \\
\text { (PROJUR) }\end{array}$ \\
\end{tabular} & $\begin{array}{l}\text { Procuradoria Jurídica } \\
\text { (PROJUR) }\end{array}$ \\
\hline $\begin{array}{l}\text { Planejamento, assessoramento, acompanhamento, } \\
\text { execução e avaliação das ações relacionadas ao de- } \\
\text { senvolvimento e organização institucional, com o } \\
\text { uso da Tecnologia de Informação e Comunicação. }\end{array}$ & $\begin{array}{l}\text { Unidade de Desenvol- } \\
\text { vimento Organizacional } \\
\text { (UDO) }\end{array}$ & $\begin{array}{l}\text { Unidade de Desenvol- } \\
\text { vimento Organizacio- } \\
\text { nal (UDO) }\end{array}$ \\
\hline
\end{tabular}

Fonte: Elaborado pelas autoras, 2020.

A parte estruturante da UNEB foi mantida e concentrada nos órgãos da administração superior. A única diferença apontada consiste na incorporação de competências do CONSAD ao CONSU 
em decorrência da promulgação da mencionada Lei Estadual n ${ }^{\circ}$ 13.466/2015, que revogou a Lei Estadual no $7176 / 1997$.

Entretanto a expansão da Universidade após a criação de novos campi e cursos, com a ampliação das vagas de ingressantes nos cursos, além da oferta de serviços motivou criação de novos órgãos na estrutura organizacional, conforme detalhamento no Quadro 2. De início, observa-se a criação da Pró-Reitoria de Gestão e Desenvolvimento de Pessoas (PGDP), desmembrada da Pró-Reitoria de Administração (PROAD), com as atribuições de "Assessoramento técnico-administrativo, planejamento, gerenciamento, execução, acompanhamento e controle das atividades de gestão e desenvolvimento dos servidores docentes e técnicos administrativos". (UNIVERSIDADE DO ESTADO DA BAHIA, 2013)

Acompanhando o crescimento dos campi e com as demandas pela manutenção dos prédios em que estavam instalados os Departamentos da UNEB, foi necessária a descentralização das ações de infraestrutura. Desta forma, foi criada a Pró-Reitoria de Infraestrutura (PROINFRA), desmembrada da Pró-Reitoria de Administração (PROAD), com as funções de "Elaboração, acompanhamento e avaliação da execução de projetos arquitetônicos, de engenharia, elétricos, hidráulicos, de rede de comunicações, urbanísticos e paisagísticos". (UNIVERSIDADE DO ESTADO DA BAHIA, 2013)

Das mudanças na estrutura da UNEB a que teve maior impacto político e educacional foi a criação da Pró-Reitoria de Ações Afirmativas (PROAF) que passou a desempenhar funções inerentes, anteriormente aos seguintes órgãos Pró-Reitoria de Ensino de Graduação (PROGRAD), Pró-Reitoria de Pesquisa e Ensino de Pós-graduação (PPG), Pró-Reitoria de Extensão (PROEX) e Pró-Reitoria de Planejamento (PROPLAN). Coube então a PROAF as funções de "Gerenciamento, assessoramento, execução, acompanhamento, controle e avaliação das ações relacionadas com a inclusão, promoção de igualdade, de garantia de equidade e de justiça social no âmbito da comunidade universitária". (UNIVERSIDADE DO ESTADO DA BAHIA, 2014). A criação da PROAF oferece uma nova forma de ingresso na UNEB através do sistema de cotas e das ações de defesa dos direitos humanos e das minorias. Nesta linha, a criação da Pró-Reitoria de Assistência Estudantil (PRAES) trouxe consigo ações relacionadas à permanência discente na Universidade, seja através da participação em Programas e estágios, seja através de auxílio à residência e viagens para participação em eventos.

\section{plurais}


QUADRO 2. Órgãos Criados na Estrutura da UNEB no período 2006 a 2015

\begin{tabular}{|c|c|c|}
\hline Atribuição & $\begin{array}{l}\text { Competência na Estrutura } \\
\text { Organizacional em } 2005\end{array}$ & $\begin{array}{c}\text { Competência na } \\
\text { Estrutura Or- } \\
\text { ganizacional em } \\
2006 \text { a } 2015\end{array}$ \\
\hline $\begin{array}{l}\text { Gerenciamento, assessoramento, execução, } \\
\text { acompanhamento, controle e avaliação das ações } \\
\text { relacionadas com a inclusão, promoção de igual- } \\
\text { dade, de garantia de equidade e de justiça social } \\
\text { no âmbito da comunidade universitária. }\end{array}$ & $\begin{array}{l}\text { Pró-Reitoria de Ensino de } \\
\text { Graduação (PROGRAD), Pró- } \\
\text { Reitoria de Pesquisa e Ensino } \\
\text { de pós-graduação (PPG), Pró- } \\
\text { Reitoria de Extensão (PRO- } \\
\text { EX) e Pró-Reitoria de Planeja- } \\
\text { mento (PROPLAN) }\end{array}$ & $\begin{array}{l}\text { Pró-Reitoria de } \\
\text { Ações Afirmativas } \\
\text { (PROAF) }\end{array}$ \\
\hline Execução orçamentaria, financeira e contábil. & $\begin{array}{l}\text { Pró-Reitoria de Administração } \\
\text { (PROAD) }\end{array}$ & $\begin{array}{l}\text { Secretaria Especial } \\
\text { de Contabilidade } \\
\text { e Finanças (SE- } \\
\text { CONF) }\end{array}$ \\
\hline $\begin{array}{l}\text { Assessoramento técnico, voltado à normatização, } \\
\text { orientação e realização dos procedimentos licita- } \\
\text { tórios, celebração e acompanhamento de contra- } \\
\text { tos e convênios. }\end{array}$ & $\begin{array}{l}\text { Pró-Reitoria de Administração } \\
\text { (PROAD) e Pró-Reitoria de } \\
\text { Planejamento (PROPLAN) }\end{array}$ & $\begin{array}{l}\text { Secretaria Especial } \\
\text { de Licitações e } \\
\text { Contratos e Convê- } \\
\text { nios (SELCC) }\end{array}$ \\
\hline $\begin{array}{l}\text { Assessoramento técnico-administrativo, plane- } \\
\text { jamento, gerenciamento, execução, acompanha- } \\
\text { mento e controle das atividades de gestão e de- } \\
\text { senvolvimento dos servidores docentes e técnicos } \\
\text { administrativos. }\end{array}$ & $\begin{array}{l}\text { Pró-Reitoria de Administração } \\
\text { (PROAD) }\end{array}$ & $\begin{array}{l}\text { Pró-Reitoria de } \\
\text { Gestão e Desenvol- } \\
\text { vimento de Pessoas } \\
\text { (PGDP) }\end{array}$ \\
\hline $\begin{array}{l}\text { Elaboração, acompanhamento e avaliação da exe- } \\
\text { cução de projetos arquitetônicos, de engenharia, } \\
\text { elétricos, hidráulicos, de rede de comunicações, } \\
\text { urbanísticos e paisagísticos. }\end{array}$ & $\begin{array}{l}\text { Pró-Reitoria de Administração } \\
\text { (PROAD) }\end{array}$ & $\begin{array}{l}\text { Pró-Reitoria de } \\
\text { Infraestrutura } \\
\text { (PROINFRA) }\end{array}$ \\
\hline $\begin{array}{l}\text { Assessoramento, divulgação, proposição, acom- } \\
\text { panhamento, apoio, regulamentação e avaliação } \\
\text { das ações de internacionalização. }\end{array}$ & $\begin{array}{l}\text { Gabinete do Reitor, Pró-Rei- } \\
\text { toria de Pesquisa e Ensino } \\
\text { de pós-graduação (PPG), } \\
\text { Pró-Reitoria de Planejamento } \\
\text { (PROPLAN) }\end{array}$ & $\begin{array}{l}\text { Secretaria Especial } \\
\text { de Relações Inter- } \\
\text { nacionais (Serint) }\end{array}$ \\
\hline $\begin{array}{l}\text { Promoção da articulação entre a Administração } \\
\text { Superior e os diversos campi e comunidades, } \\
\text { bem como, os poderes públicos e respectivos } \\
\text { órgãos, entidades privadas, órgãos não-governa- } \\
\text { mentais. }\end{array}$ & Gabinete do Reitor & $\begin{array}{l}\text { Secretaria Especial } \\
\text { de Articulação } \\
\text { Interinstitucional } \\
\text { (SEAI) }\end{array}$ \\
\hline
\end{tabular}




\begin{tabular}{|l|l|l|}
\hline $\begin{array}{l}\text { Órgão vinculado ao Gabinete da Reitoria, res- } \\
\text { ponsável pela concepção de diretrizes, apoio } \\
\text { acadêmico e técnico aos processos avaliativos no } \\
\text { âmbito da Universidade (UNIVERSIDADE DO } \\
\text { ESTADO DA BAHIA, 2014). }\end{array}$ & $\begin{array}{l}\text { Pró-Reitoria de Ensino de } \\
\text { Graduação (PROGRAD), Pró- } \\
\text { Reitoria de Pesquisa e Ensino } \\
\text { de Pós-graduação (PPG), Pró- } \\
\text { Reitoria de Extensão (PRO- } \\
\text { EX) e Pró-Reitoria de Planeja- } \\
\text { mento (PROPLAN) }\end{array}$ & $\begin{array}{l}\text { Secretaria de Ava- } \\
\text { liação Institucional } \\
\text { (SEAVI) }\end{array}$ \\
\hline $\begin{array}{l}\text { Promoção da educação a distância, na graduação, } \\
\text { pós-graduação e extensão, em consonância com } \\
\text { as Pró-Reitorias acadêmicas e departamentos. }\end{array}$ & $\begin{array}{l}\text { Pró-Reitoria de Ensino de } \\
\text { Graduação (PROGRAD), Pró- } \\
\text { Reitoria de Pesquisa e Ensino } \\
\text { de Pós-graduação (PPG) e } \\
\text { Pró-Reitoria de Extensão } \\
\text { (PROEX) }\end{array}$ & $\begin{array}{l}\text { Unidade Acadêmi- } \\
\text { ca de Educação a } \\
\text { Distância (Unead) }\end{array}$ \\
\hline
\end{tabular}

Fonte: Elaborado pelas autoras, 2020.

Dentre as alterações realizadas na estrutura da UNEB nos últimos anos, duas outras merecem destaque, visto que são estruturais para o seu desenvolvimento institucional. A primeira delas é a criação da Secretaria de Avaliação Institucional (SEAVI), desmembrada da Pró-Reitoria de Ensino de Graduação (PROGRAD), Pró-Reitoria de Pesquisa e Ensino de Pós-graduação (PPG), Pró-Reitoria de Extensão (PROEX) e Pró-Reitoria de Planejamento (PROPLAN) e com as funções de, como "órgão vinculado ao Gabinete da Reitoria, responsável pela concepção de diretrizes, apoio acadêmico e técnico aos processos avaliativos no âmbito da Universidade" (UNIVERSIDADE DO ESTADO DA BAHIA, 2014).

A implementação da avaliação institucional foi uma decisão de governo para definição das prioridades de investimentos. As avaliações passaram a ser realizadas através da análise de indicadores específicos, bem como através do Exame Nacional de Desempenho dos Estudantes (ENADE), que integra o Sistema Nacional de Avaliação da Educação Superior (SINAES). A avaliação busca a verificação da qualidade dos profissionais formados pelas instituições, mas também buscam adentrar pelo cotidiano institucional através das visitas técnicas quando são verificados os planos de cursos, material disponível como laboratórios e bibliotecas. (BRASIL, 2004).

Por fim, uma mudança importante diante do crescimento do uso das tecnologias da informação, aplicadas ao ensino, bem como a expansão dos cursos na modalidade à distância foi necessária a criação de uma Unidade Acadêmica de Educação a Distância (UNEAD), como parte

\section{plurais}


Pró-Reitoria de Ensino de Graduação (PROGRAD), Pró-Reitoria de Pesquisa e Ensino de Pós-graduação (PPG) e Pró-Reitoria de Extensão (PROEX). O que anteriormente estava disperso em várias Pró-Reitorias passaram a compor um único órgão responsável pela promoção “da educação a distância, na graduação, pós-graduação e extensão, em consonância com as Pró-Reitorias acadêmicas e departamentos". (UNIVERSIDADE DO ESTADO DA BAHIA, 2014).

Além disso, a informatização dos procedimentos, as distâncias entre os departamentos da administração central contribuíram para a valorização das tecnologias da informação no cotidiano universitário, tornando uma ferramenta estruturante do processo organizacional.

\section{Considerações Finais}

O estudo sobre as modificações da estrutura organizacional da Universidade do Estado da Bahia, entre os anos de 2005 e 2015 contribui para elucidar as discussões sobre como as instituições podem e devem acompanhar os objetivos da instituição, e diálogo com as demandas externas para alcançar a excelência nas suas atividades fins e meio. A expansão da UNEB seja na oferta de cursos destinada à formação profissional, formação continuada ou titulação, o alargamento das áreas de pesquisa e, consequentemente o aumento da atuação junto às suas comunidades nas atividades da extensão, levou a ajustes na sua estrutura organizacional, sem, entretanto, abdicar da identidade e institucionalidade da Universidade, na administração e nos campi, através de seus órgãos colegiados e Reitoria e Pró-Reitorias.

A discussão foi motivada pelo questionamento: quais as estratégias adotadas pela Universidade do Estado da Bahia (UNEB) para alterar a sua estrutura organizacional? Considerando o modelo multicampi da unidade de estudo, a pesquisa sobre as alterações na estrutura organizacional utilizou como referência o modelo multicampi, em decorrência dos vinte quatro campi, suas comunidades e suas especificidades.

Contribuiu também a discussão concernente à estrutura acadêmica e administrativa, com detalhe ao sistema de fluxo de decisão em uma organização que contempla o núcleo operacional, a cúpula estratégica, linha intermediária, tecnoestrutura e a assessoria de apoio, combinada com a análise das diversas estruturas organizacionais previstas na literatura. Das estruturas constatadas, identifica-se maior aproximação com o modelo burocrático profissional, o qual respalda a atuação

\section{plurais}

Salvador, v. 5, n. 1, p. 96-122, jan./abr. 2020 
dos professores em áreas específicas de conhecimento, e a colegialidade, com decisões a partir do grupo, previsto na legislação brasileira.

Observa-se que as alterações na estrutura organizacional resultaram em criação de órgãos e transferência de atribuições para outros órgãos, em decorrência da legislação, no caso específico do Conselho de Administração (CONSAD), que teve suas atribuições assumidas pelo Conselho Universitário (CONSU).

De outra forma, a UNEB no intento de atingir o objetivo de promover a formação integral do cidadão e o desenvolvimento das potencialidades econômicas, tecnológicas, sociais, culturais, artísticas e literárias da comunidade baiana, sob a égide dos princípios da ética, da democracia, das ações afirmativas, da justiça social, pluralidade étnico-cultural e demais princípios do Direito Público, conforme mencionado anteriormente, as alterações na estrutura organizacional foram demandadas por conjunturas políticas administrativas com a finalidade de atender às suas demandas de forma mais ágil e específica por área de atuação, seja acadêmica ou administrativa, a exemplo da Pró-Reitoria de Ações Afirmativas, onde a mobilização da comunidade serviu de elemento alavancador do processo que teve como ponto alto a aprovação das cotas raciais para ingresso no processo seletivo.

\title{
REFERÊNCIAS
}

APPOLINÁRIO. Fábio. Dicionário de metodologia científica: um guia para a produção do conhecimento científico. São Paulo: Atlas, 2004, 300 p.

BAHIA. Decreto Estadual No 13.664 de 07 de fevereiro de 2012, dispõe sobre o Recredenciamento da Universidade do Estado da Bahia (UNEB), e dá outras providências.

BAHIA. Lei Delegada $\mathbf{N}^{\mathbf{0}}$ 66, de $1^{\circ}$ de junho de 1983.

BAHIA. Lei Estadual No 7176, de 10 de setembro de 1997.

BAHIA. Lei Estadual $\mathbf{N}^{\mathbf{0}}$ 13.466, de 22 de dezembro de 2015. Dispõe sobre a organização e funcionamento das Universidades Estaduais da Bahia, revoga a Lei $\mathrm{n}^{\circ} 7.176$, de 10 de setembro de 1997, e dá outras providências.

\author{
plurais


BOAVENTURA, Edivaldo Machado. Origem e formação do sistema estadual de educação superior da Bahia - 1968-1991. Revista da FAEEBA: Educação e contemporaneidade / Universidade do Estado da Bahia, Departamento de Educação I - v. 14, n. 24 (jul./dez., 2005), p. 155-173.

BOAVENTURA. Edivaldo Machado. A Construção da Universidade Baiana: origens, missões e afrodescendência. Salvador: EDUFBA, 2009

BRASIL. Constituição (1988). Constituição da República Federativa do Brasil: promulgada em 5 de outubro de 1988.

BRASIL, Lei Federal n 10.861, de 14 de abril de 2004, que institui o Sistema Nacional de Avaliação da Educação Superior (SINAES).

CRETELLA JÚNIOR, José, ULHOA CINTRA, Geraldo. Dicionário Latino-Português. São Paulo: Companhia, Editora Nacional, 1953, p.169.

FIALHO, Nadia Hage. Universidade Multicampi. Brasília: Plano Editora/Autores Associados, 2005.

FINGER, Almeri Paulo, Gestão Acadêmica In: FINGER, Almeri P. (Org.). Universidade: Organização e Planejamento. Florianópolis: UFSC/CPGA/NUPEAU, 1988, p. 71-88.

HARDY, Cynthia e FACHIN, Roberto. Gestão Estratégica na Universidade Brasileira. 2 ed. Porto Alegre: Ed. Universitária/UFRGS, 2000.

HOUAISS, Antonio; VILLAR, Mauro de Salles. Dicionário Houaiss da língua portuguesa. Rio de Janeiro: Objetiva, 2001.

LACOMBE, Francisco José Masset; HEILBORN, Gilberto Luiz José. Administração: Princípios e Tendências. 2 ed. rev. e atualizada. São Paulo: Saraiva, 2008.

MINTZBERG, Henry. Criando Organizações Eficazes: estruturas em cinco configurações; trad. Ailton Bonfim Brandão - 2 ed. São Paulo: Atlas, 2003.

UNIVERSIDADE DO ESTADO DA BAHIA. Conselho Universitário (CONSU) Resolução n. ${ }^{\circ}$ 324/05, aprova as alterações do Regimento Geral da UNEB.

UNIVERSIDADE DO ESTADO DA BAHIA. Conselho Universitário (CONSU) Resolução n. ${ }^{\circ}$ 864/11, aprova os ajustes e adequações promovidos no Regimento Geral da UNEB, deliberado pela Resolução CONSU n ${ }^{\circ}$ 792/2010, em atendimento à diligência do CEE-BA.

UNIVERSIDADE DO ESTADO DA BAHIA. Conselho Universitário (CONSU) Resolução n. ${ }^{\mathbf{1}} \mathbf{1 0 0 6 / 2 0 1 3}$, aprova o Regimento Interno das Pró-Reitorias e Unidade de Desenvolvimento Organizacional (UDO) da UNEB.

\section{plurais}


UNIVERSIDADE DO ESTADO DA BAHIA. Conselho Universitário (CONSU), Resolução n. ${ }^{\circ}$ 1023/2014, aprova a criação e implantação da Pró-Reitoria de Ações Afirmativas (PROAF) da UNEB.

UNIVERSIDADE DO ESTADO DA BAHIA. Conselho Universitário (CONSU), Resolução n. ${ }^{\mathbf{1 0}} \mathbf{1 0 2 4} / \mathbf{2 0 1 4}$, aprova a criação e implantação da Secretaria Especial de Licitações, Contratos e Convênios (SELCC) da UNEB.

UNIVERSIDADE DO ESTADO DA BAHIA. Conselho Universitário (CONSU) Resolução n. ${ }^{\circ}$ 1025/2014, aprova a criação e implantação da Secretaria Especial de Articulação Interinstitucional (SEAI) da UNEB.

UNIVERSIDADE DO ESTADO DA BAHIA. Conselho Universitário (CONSU) Resolução n. ${ }^{\circ}$ 1.026/2014, aprova a criação e implantação da Secretaria Especial de Avaliação Institucional (SEAVI) da UNEB.

UNIVERSIDADE DO ESTADO DA BAHIA. Conselho Universitário (CONSU) Resolução n..$^{0}$ 1027/14, aprova a criação e implantação da Secretaria Especial de Relações Internacionais (SERINT) da UNEB.

UNIVERSIDADE DO ESTADO DA BAHIA. Conselho Universitário (CONSU) Resolução n. ${ }^{0}$ 1.051/2014, aprova a criação e implantação da Unidade Acadêmica de Educação a Distância (UNEAD) da UNEB.

UNIVERSIDADE DO ESTADO DA BAHIA. Conselho Universitário (CONSU) Resolução n. ${ }^{\circ}$ 1.106/2015, aprova a criação e implantação da Secretaria Especial de Contabilidade e Finanças (SECONF) da UNEB.

Recebido em: 15 de abril de 2020.

Inserido em: 20 de maio de 2020.

Esta obra está licenciada com uma Licença Creative Commons Atribuição 4.0 Internacional. 